\title{
The Spleen Contributes Stem Cells to Peripheral Blood Stem Cell Transplants
}

\author{
Toshiyuki Mera1, Shelly Heimfeld ${ }^{2}$ and Denise L Faustman ${ }^{1 *}$
}

${ }^{1}$ Department of Medicine, Harvard Medical School and Massachusetts General Hospital, Boston, Massachusetts, USA

${ }^{2}$ Department of Medicine, Immunobiology Laboratories and Boston, Massachusetts, Fred Hutchinson Cancer Research Center, Clinical Research Division, Seattle, Washington, USA

\begin{abstract}
Treatment of malignancies with Peripheral Blood Stem Cell Transplants (PBSCTs) from donors given GranulocyteColony-Stimulating-Factor (G-CSF) has improved survival relative to bone marrow transplants. G-CSF mobilizes CD34+ hematopoietic stem cells from bone marrow into the blood. Enrichment of PBSCT by purification of CD34+ stem cells fails to produce superior clinical benefits. We hypothesize that the reason why CD34+-enriched PBSCTs are not more effective is because the enrichment and purification process leaves out G-CSF-mobilized stem cells from another source, the spleen, which holds a unique reservoir of Hox11+ stem cells. Quantitative mRNA analysis was used to determine whether G-CSF mobilizes Hox11+ stem cells and whether expression occurs in a cell population distinct from CD34+ cells. Samples of peripheral blood lymphocytes (PBLs) were obtained from ten normal untreated donors and 18 normal donors treated with G-CSF. G-CSF was found to mobilize both CD34+ stem cells $(p=0.02)$ and even more dramatically mobilize Hox $11+$ splenic stem cells $(p=0.000013)$ into the peripheral blood. The findings support the hypothesis that G-CSF mobilizes two distinct stem cell populations, one from the bone marrow and the other from the spleen. The inferior clinical performance of CD34+-enriched and purified PBSCTs compared to unenriched PBSCTs may be explained by the omission of Hox11+ stem cells. These findings suggest that PBSCTs without enrichment and purification of CD34+ may improve treatment of cancer and potentially other diseases in tissues derived from Hox11+ stem cells.
\end{abstract}

Keywords: Bone marrow transplantation; Granulocyte-Colony Stimulating Factor (G-CSF); Peripheral Blood Stem Cell Transplants (PBSCT); Peripheral Blood Lymphocytes (PBLs); CD34; Hox11 (Tlx1); Graft Versus Host Disease (GVHD)

\section{Introduction}

Treatment of malignancies with allogeneic peripheral blood stem cell transplants (PBSCTs) from donors given granulocyte-colonystimulating-factor (G-CSF) has decreased relapse rates and improved or maintained survival compared to bone marrow transplants, although graft versus host disease (GVHD) still occurs [1]. For autologous stem cell transplants, the use of autologous PBSCT from G-CSF stimulation also in multiple studies shows faster recovery of neutrophils and platelets, and fewer days to transfusion independence but with no differences in survival [2-5]. G-CSF mobilizes CD34+ hematopoietic stem cells from bone marrow into the blood. Further enrichment of PBSCT by purification of $\mathrm{CD} 34^{+}$stem cells does not generate superior clinical benefits and in some cases shows slower white blood cell recovery with increased infections due to poor immune reconstitution [6,7]. We hypothesize that the reason why CD34 ${ }^{+}$-enriched PBSCT are not more effective is because the enrichment process leaves out G-CSF-mobilized stem cells from another source, the spleen.

The adult spleen harbors throughout life stem cells expressing the Hox 11 oncogene, also known as Tlx1 [8]. Adult human bone marrow lacks Hox 11 stem cells [8]. Hox 11 is an embryonic transcription factor not found in bone marrow but persistse throughout life in the adult human spleen. Hox 11 was first identified in association with cancers including $\mathrm{T}$ cell acute lymphocytic leukemia but more recent research shows all humans harbor Hox11 expressing stem cells in their spleen throughout their life $[8,9]$.

Hox 11 plays an important role in development of cell differentiation during which it activates a cascade of genes controlling cell fate and cell differentiation. In various human and animal models, Hox $11^{+}$stem cells robustly differentiate into functional cells of multiple lineages, including cranial neurons, hematopoietic cells, pancreatic islets, bone and salivary glands [10]. The spleen also uniquely contributes to complete B cell memory [11]. The stem cells of the spleen allow for full maturation of immature transitional B cells into naive B cells. The later step is unique to splenic function since splenectomy results in similar accumulations of naïve B cells, reduction of memory B cells and well-known susceptibilities to select infections [12]. Interestingly, this immature peripheral phenotype was similar to bone marrow transplants before G-CSF. Our hypothesis about a splenic stem cell contribution to PBSCT also derives from the observation that G-CSF mobilizations induce splenomegaly in most donors and in rare, severe cases splenic rupture $[13,14]$. Splenomegaly might reflect dramatic G-CSF-induced Hox $11^{+}$stem cell proliferation. We examine by quantitative mRNA analysis whether G-CSF mobilizes Hox $11^{+}$stem cells and whether expression occurs in a cell population distinct from $\mathrm{CD} 34^{+}$cells. We need only assay for Hox11+ and CD34+ transcripts because these markers are unique to splenic and bone marrow stem cells, respectively $[15,16]$. Published data of the complete and unique proteomic signature of adult Hox11 stems has been reported [16].

*Corresponding author: Denise L Faustman, Harvard Medical School and Massachusetts General Hospital, Boston, Massachusetts, USA, Tel: 617-7264084; Fax: 617-726-4095; E-mail: faustman@helix.mgh.harvard.edu

Received November 07, 2014; Accepted December 08, 2014; Published December 10, 2014

Citation: Mera T, Heimfeld S, Faustman DL (2014) The Spleen Contributes Stem Cells to Peripheral Blood Stem Cell Transplants. J Stem Cell Res Ther 4: 253. doi:10.4172/2157-7633.1000253

Copyright: (c) 2014 Mera T, et al. This is an open-access article distributed under the terms of the Creative Commons Attribution License, which permits unrestricted use, distribution, and reproduction in any medium, provided the original author and source are credited. 


\section{Materials and Methods}

\section{Patients}

Human peripheral blood lymphocytes (PBLs) used for this study were from the Core Center of Excellence in Hematology (CCEH) at the Fred-Hutchison-Cancer-Research Center or Massachusetts General Hospital (MGH) (FHRC-985.03C/MGH-2001P001379).

\section{Methods}

We extracted total RNA from PBLs from G-CSF treated or nontreated donors using the RNeasy Mini kit (QIAGEN). The generated cDNA with the High Capacity cDNA Reverse Transcription Kit allowed quantitative real-time PCR using Power SYBR-Green and 7000 RealTime-PCR (Applied Biosystems). PBLs and the Beta-Actin housekeeper gene were used to normalize data and relative expression was calculated using the ddCT method. HOX11/TLX1 (GeneID; 3195) specific primers were forward sequence:5'-GGTTCACAGGTCACCCCTATC $-3^{\prime}$ and reverse sequence: 5'- GTCTGCCGTCTCCACTTTGTC - 3'. The beta-actin (Gene ID;60) primers were forward sequence: 5'-CATGTACGTTGCTATCCAGGC and reverse sequence:5'CTCCTTAATGTCACGCACGAT-3'. The CD34 (Gene ID;947) primers were forward sequence:5'-CTACAACACCTAGTACCCTTGGA-3', reverse sequence:5'- GGTGAACACTGTGCTGATTACA-3'. All primers were purchased from Custom DNA Oligos (Invitrogen). The ALL-SIL cell line (DSMZ) that expresses HOX11/TLX1 was a positive control for the TLX1 primers.

\section{Statistical analysis}

All data analysis to determine the statistical significance was calculated using an unpaired t-test. Statistical significance was viewed as a $\mathrm{p}$ value $<0.05$. Calculations were performed in GraphPad Prism -5 software.

\section{Results}

Ten normal human donors provided untreated samples of peripheral blood lymphocytes (PBLs) and 18 donors provided samples of G-CSF-mobilized PBLs. G-CSF mobilized into the blood circulation both $\mathrm{CD} 34^{+}$bone derived stem cells $(\mathrm{p}=0.02)$ and Hox $11^{+}$derived splenic stem cells $(\mathrm{p}=0.000013)$ compared with non-mobilized PBLs (Figure 1). The relative increase of mobilized Hox11-derived splenic stem cells was very large in comparison to the CD34 stem cells (Figure 1). To rule out the possibility that Hox 11 is co-expressed on $\mathrm{CD} 34^{+}$cells after G-CSF treatment, we examined G-CSF-mobilized unmanipulated and $\mathrm{CD} 34^{+}$-enriched samples (Figure 2). We found that the enrichment process only resulted in dramatically increased $\mathrm{CD}^{+} 4^{+}$expression $(\mathrm{p}<0.0001)$; these enriched cells do not express Hox $11^{+}(\mathrm{P}<0.02)$ (Figure 2). Therefore G-CSF mobilizes two non-overlapping populations of stem cells.

\section{Discussion}

Our findings support the hypothesis that G-CSF mobilizes at least two distinct and non-overlapping populations of stem cells, CD $34^{+}$ hematopoietic stem cells from bone marrow and Hox $11^{+}$stem cells
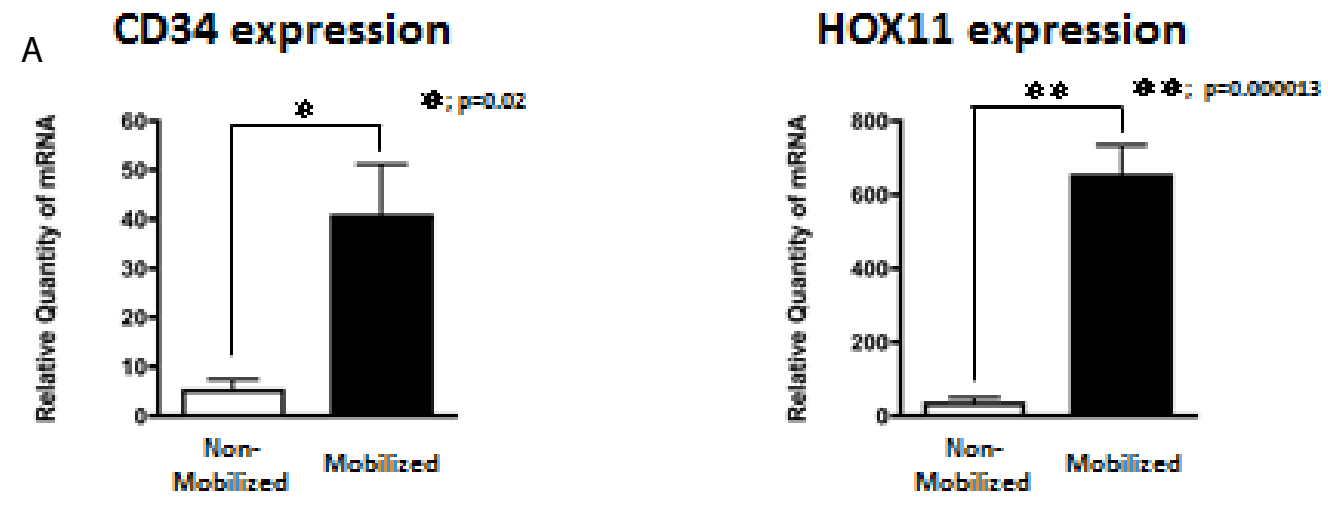

B
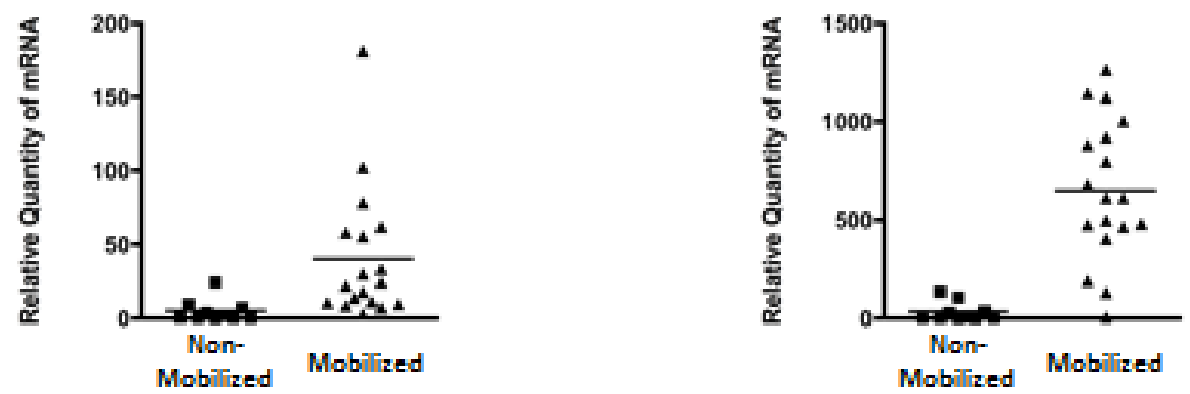

Figure 1: $\mathrm{CD}_{3} 4^{+}$and $\mathrm{HOX} 11^{+} \mathrm{mRNA}$ expression in peripheral blood lymphocytes (PBLs) from normal untreated donors ( $\mathrm{n}=10$ ) versus $\mathrm{C}$-GSF-mobilized donors ( $\mathrm{n}=18$ ). G-CSF mobilizes both Hox 11 and CD34+ stem cells into the circulation. (a) The left panel shows CD $34^{+}$mRNA representing the means \pm minus the standard errors of the means of the pooled samples. The right panel shows Hox $11^{+} \mathrm{mRNA}$ representing the means \pm minus the standard errors of the means of the pooled samples. (b) The left and right panels represent the individual data points of the subjects used for the pooled data in A. 


\section{CD34 expression}

A

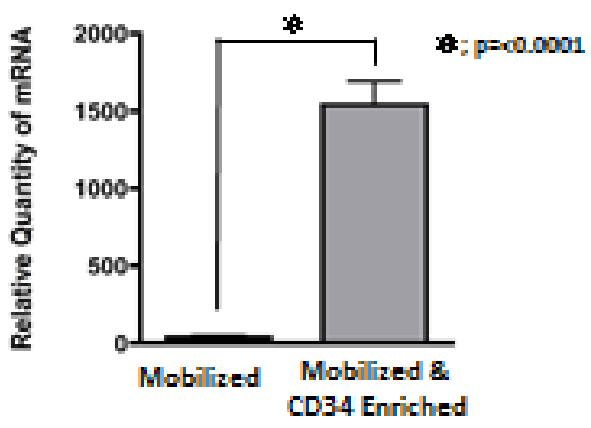

B

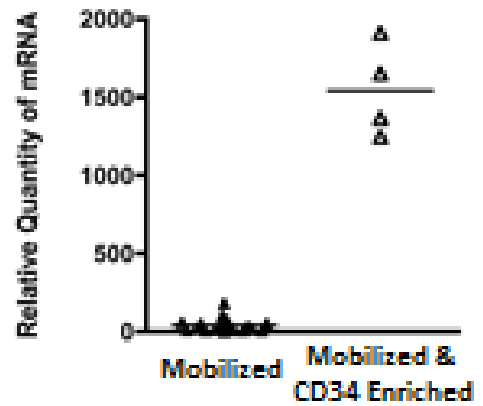

HOX11 expression
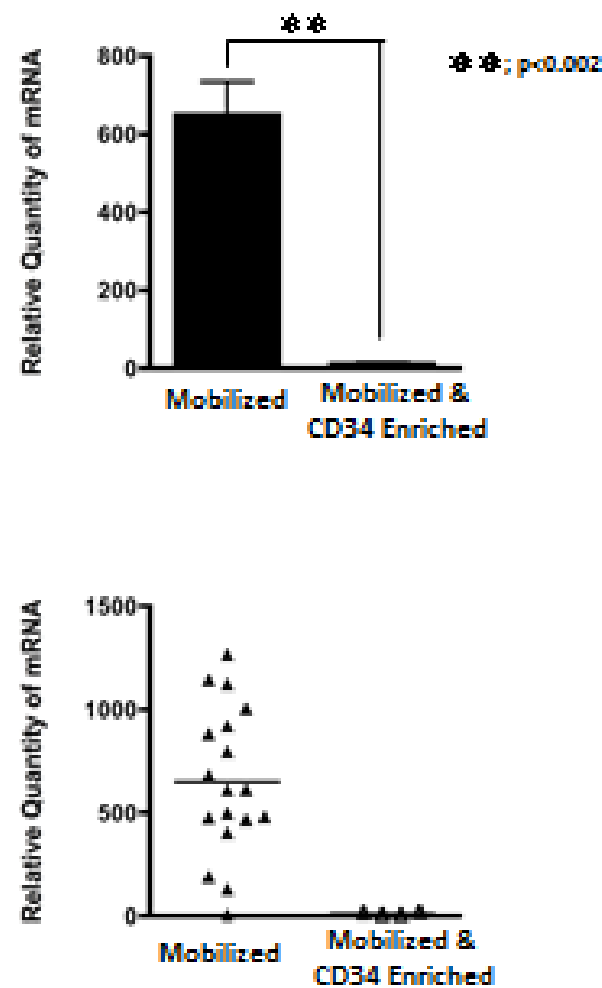

Figure 2: The effect of CD34+ enrichment of G-CSF-mobilized PBLs on the expression of CD34 or Hox11. Bone marrow-derived CD34 ${ }^{+}$stem cells are a distinct stem cell population from splenic derived Hox $11^{+}$stem cells (a) The left panel shows CD $34^{+} \mathrm{mRNA}$ means plus \pm minus the standard errors of the means of the pooled samples. The right panel shows Hox11+ mRNA means plus \pm minus the standard errors of the means of the pooled samples. (b) The left and right panels display the individual data points of the single subject samples used for the pooled data in $A$. $n=18$ samples from normal G-CSF-treated donors. $n=4$ samples for the mobilized and CD34+-enriched samples from G-CSF treated donors.

from the spleen. The very dramatic mobilization of splenic stem cells suggests that G-CSF's well-known advantage over bone marrow for stem cell transplantation protocols may be due to two stem cell populations, including the less differentiated stem cells of the spleen with broad hematopoietic reconstitution abilities $[9,11,12,16,17]$. Indeed, prior to this data it was viewed that the common occurrence of splenomegaly after G-CSF treatment was an adverse outcome that could on rare occasions result in splenic rupture; instead it may well be the case the G-CSF is mobilizing immature stem cells, mature neutrophils and other beneficial splenic populations [18-20]. Since Hox11 splenic stem cells are known to have multi-lineage potential, represent the embryonic precursor to bone marrow stem cells and in adults also contain unique B cell populations for fighting infections and complete B cell memory, our findings may help clinicians improve PBSCTs for the treatment of cancer and potentially other diseases [21-23].

\section{Acknowledgments}

We are indebted to The lacocca Foundation for their support of this project Dr. Miriam Davis of our group contributed to the proof reading of this paper and Ms. Lynne Murphy provided manuscript preparation assistance.

\section{References}

1. Stem Cell Trailists' Collaborative Group (2005) Allogeneic peripheral blood stem-cell compared with bone marrow transplantation in the management of hematologic malignancies; an individual patient data meta-analysis of nine randomized trials. J Clin Oncol 23: 5074-5087. [PubMed]

2. Hartmann O, Le Corroller AG, Blaise D, Michon J, Philip I, et al. (1997)
Peripheral blood stem cell and bone marrow transplantation for solid tumors and lymphomas: hematologic recovery and costs. A randomized, controlled trial. Ann Intern Med 126: 600-607. [PubMed]

3. Beyer J, Schwella N, Zingsem J, Strohscheer I, Schwaner I, et al. (1995) Hematopoietic rescue after high-dose chemotherapy using autologous peripheral-blood progenitor cells or bone marrow: a randomized comparison. $J$ Clin Oncol 13: 1328-1335. [PubMed]

4. Dreger P, Klöss M, Petersen B, Haferlach T, Löffler H, et al. (1995) Autologous progenitor cell transplantation: prior exposure to stem cell-toxic drugs determines yield and engraftment of peripheral blood progenitor cell but not of bone marrow grafts. Blood 86: 3970-3978. [PubMed]

5. Schmitz N, Linch DC, Dreger P, Goldstone AH, Boogaerts MA, et al. (1996) Randomised trial of filgrastim-mobilised peripheral blood progenitor cell transplantation versus autologous bone-marrow transplantation in lymphoma patients. Lancet 347: 353-357. [PubMed]

6. Stewart AK, Vescio R, Schiller G, Ballester O, Noga S, et al. (2001) Purging of autologous peripheral-blood stem cells using CD34 selection does not improve overall or progression-free survival after high-dose chemotherapy for multiple myeloma: results of a multicenter randomized controlled trial. J Clin Oncol 19: 3771-3779. [PubMed]

7. Bourhis JH, Bouko Y, Koscielny S, Bakkus M, Greinix H, et al. (2007) Relapse risk after autologous transplantation in patients with newly diagnosed myeloma is not related with infused tumor cell load and the outcome is not improved by CD34+ cell selection: long term follow-up of an EBMT phase III randomized study. Haematologica 92: 1083-1090. [PubMed]

8. Dieguez-Acuna FJ, Gygi SP, Davis M, Faustman DL (1991) Splenectomy: a new treatment option for ALL tumors expressing Hox-11 and a means to test the stem cell hypothesis of cancer in humans. Leukemia 21: 2192-2194. [PubMed] 
Citation: Mera T, Heimfeld S, Faustman DL (2014) The Spleen Contributes Stem Cells to Peripheral Blood Stem Cell Transplants. J Stem Cell Res Ther 4: 253. doi:10.4172/2157-7633.1000253

9. Hatano M, Roberts CW, Minden M, Crist WM, Korsmeyer SJ (1991) Deregulation of a homeobox gene, HOX11, by the $\mathrm{t}(10 ; 14)$ in T cell leukemia. Science 253: 79-82. [PubMed]

10. Lonyai A, Kodama S, Burger D, Davis M, Faustman DL (2008) The promise of Hox11+ stem cells of the spleen for treating autoimmune diseases. Horm Metab Res 40: 137-146. [PubMed]

11. Kruetzmann S, Rosado MM, Weber $\mathrm{H}$, Germing $U$, Tournilhac $\mathrm{O}$, et al. (2003) Human immunoglobulin M memory B cells controlling Streptococcus pneumoniae infections are generated in the spleen. J Exp Med 197: 939-945. [PubMed]

12. Mamani-Matsuda M, Cosma A, Weller S, Faili A, Staib C, et al. (2008) The human spleen is a major reservoir for long-lived vaccinia virus-specific memory B cells. Blood 111: 4653-4659. [PubMed]

13. Veerappan R, Morrison M, Williams S, Variakojis D (2007) Splenic rupture in a patient with plasma cell myeloma following G-CSF/GM-CSF administration for stem cell transplantation and review of the literature. Bone Marrow Transplant 40: 361-364. [PubMed]

14. Stroncek DF, Dittmar K, Shawker T, Heatherman A, Leitman SF (2004) Transient spleen enlargement in peripheral blood progenitor cell donors given G-CSF. J Transl Med 2: 25. [PubMed]

15. Simmons DL, Satterthwaite AB, Tenen DG, Seed B (1992) Molecular cloning of a cDNA encoding CD34, a sialomucin of human hematopoietic stem cells. $J$ Immunol 148: 267-271. [PubMed]

16. Dieguez-Acuna F, Kodama S, Okubo Y, Paz AC, Gygi SP, et al. (2009) Proteomics identifies multipotent and low oncogenic risk stem cells of the spleen. Int J Biochem Cell Biol 42: 1651-1660. [PubMed]
17. Faustman DL, Giesecke C, Davis M, Kuhtreiber WM, Tran SD, et al. (2014) Disposable no longer: The spleen holds a reservoir of stem cells. J Stem Cell Res Ther 4: 219 .

18. Kiang J, Zhai M, Liao P (2014) Pegylated G-CSF Inhibits Blood Cell Depletion Increases Platelets, Blocks Splenomegaly, and Improves Survival after WholeBody lonizing Irradiation but Not after Irradiation Combined with Burn. Oxidative Medicine and Cellular Longevity.

19. Becker PS, Wagle M, Matous S, Swanson RS, Pihan G, et al. (1997) Spontaneous splenic rupture following administration of granulocyte colonystimulating factor (G-CSF): occurrence in an allogeneic donor of peripheral blood stem cells. Biol Blood Marrow Transplant 3: 45-49. [PubMed]

20. Nuamah NM, Goker H, Kilic YA, Dagmoura H, Cakmak A (2006) Spontaneous splenic rupture in a healthy allogeneic donor of peripheral-blood stem cell following the administration of granulocyte colony-stimulating factor (g-csf). A case report and review of the literature. Haematologica 91: ECR08. [PubMed]

21. Wardemann H, Boehm T, Dear N, Carsetti R (2002) B-1a B cells that link the innate and adaptive immune responses are lacking in the absence of the spleen. J Exp Med 195: 771-780. [PubMed]

22. Rosado MM, Aranburu A, Capolunghi F, Giorda E, Cascioli S, et al. (2009) From the fetal liver to spleen and gut: the highway to natural antibody. Mucosal Immunol 2: 351-361. [PubMed]

23. Tamura H, Okamoto S, Iwatsuki K, Futamata Y, Tanaka K, et al. (2002) In vivo differentiation of stem cells in the aorta-gonad-mesonephros region of mouse embryo and adult bone marrow. Experimental Hematology 30: 957-966. [PubMed] 